\title{
Effect of family reorientation messages on delirium prevention among critically ill patients
}

\author{
Nermine M. Elcokany, Fatma Refaat Ahmed \\ Faculty of Nursing, Alexandria University, Egypt
}

Received: May 6, 2019

Accepted: July 4, 2019

Online Published: July 15, 2019

DOI: $10.5430 /$ jnep.v9n10p50

URL: https://doi.org/10.5430/jnep.v9n10p50

\begin{abstract}
Background: About $50 \%-80 \%$ of critically ill patients develop delirium during their intensive care unit (ICU) stay. Adverse events associated with delirium can range from functional disability, cognitive and psychological impairment, dementia and even death. Removal of invasive lines, self-extubation, prolonged sedation and ventilation therapies which delay the ICU liberation, and increase the overall hospital length of stay are also negative squeals of delirium. Delirium has series of adverse events that are not limited to the associated morbidies and mortality, but also extended to include the burden placed on caregivers, families and healthcare services, in addition to increasing the cost of care. Using auditory stimulation as a non-pharmacological intervention can stimulate the affected neural networks, accelerate brain plasticity and avoid sensory deprivation that could induce pain, agitation, and delirium and slow down the patients' recovery. It is evident that familiar auditory stimuli by a familiar voice is eliciting more responses to auditory tones as it can grasp patients' attention without much effort and disrupts ongoing cognitive activities. Accordingly, multicomponent family reorientation strategy has recently been proposed to achieve better outcomes.

Methods: A quasi experimental research design was used in this study in which one tool was used for data collection: "Confusion Assessment Method-intensive care unit (CAM-ICU)".

Results: During the five-day intervention period, the delirium free days was all the days in the family voice group, four days in the unfamiliar voice group and no free days in the control group which indicates a significant difference among groups on number of delirium free days $\left({ }^{M C} p<.001 *\right)$.

Conclusion: Reorienting critically ill patients through recorded messages is an effective strategy to reduce the incidence of delirium. Furthermore, using a familiar family sound is more effective in reducing delirium as proved by the number of delirium free days. During the five-day intervention period, the family voice group shows more delirium free days than the unfamiliar voice group. The intervention used in this study is easy, costless and effective strategy in prevention of delirium among critically ill patients.
\end{abstract}

Key Words: Critical illness, Delirium, Delirium prevention, Nursing care, Intensive care units, Patient- and family-centered care

\section{INTRODUCTION}

In the past, present and even in the future, intensive care units (ICUs) worldwide continuously adopt critical care nursing practices to achieve the optimal level of comfort and safety for critical care potentials. The American association of critical care nurse (2015) updated its scope and standards for critical care nursing practice to include a patient- and family-centered healthcare system. ${ }^{[1]}$

From ICU admission and till discharge, critically ill patients and their families are confronting multiple challenges. Criti-

*Correspondence: Nermine M. Elcokany; Email: nermine.elcokany@alexu.edu.eg; Address: Faculty of Nursing, Alexandria University, Egypt. 
cally ill patients are admitted to ICUs to recover from their critical illness, however, they almost expose to adverse events that may lead to poor outcomes and undesired complications. ${ }^{[2]}$ Cognitive complications are among poor outcomes that may extend beyond patients' ICU stay and may lead to long-term deficit in their quality of life. ${ }^{[3,4]}$ Delirium is considered as one of the neurocognitive complications occur in ICU and about $50 \%-80 \%$ of critically ill patients develop delirium. ${ }^{[4,5]}$

Delirium is defined according to the American Psychiatric Association (2013) as "an acute change in consciousness

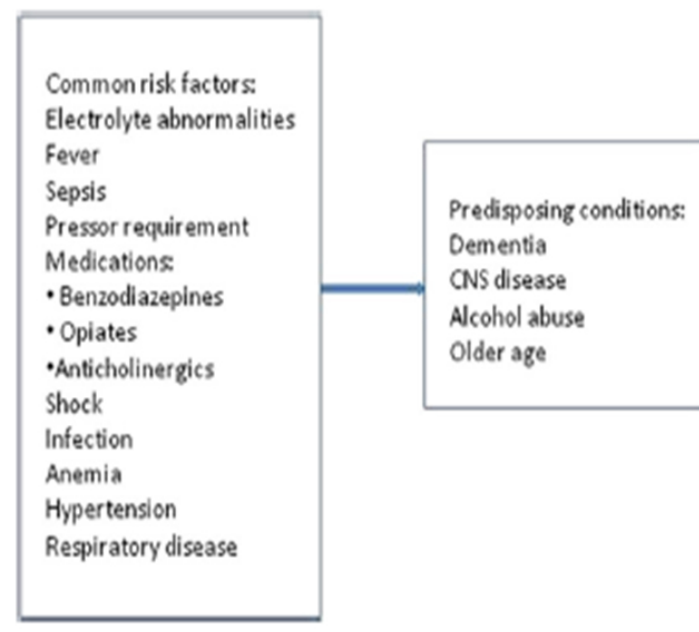

Figure 1. Factors leading to delirium ${ }^{[8]}$

Despite inconsistent prevalence rate of delirium between studies, it is evident that delirium has a negative impact among critically ill patients. Evidence shows a relationship between incidence of delirium and short and long term neurocognitive impairments. ${ }^{[7,9]}$ Adverse events associated with delirium in ICUs can range from functional disability, cognitive and psychological impairment, dementia and even death. Removal of invasive lines, self-extubation, prolonged sedation and ventilation therapies which delay the ICU liberation, and increase the overall hospital length of stay are also negative squeals of delirium. ${ }^{[7,9,10]}$ Series of delirium adverse events are not limited to the associated morbidities and mortality, but also extended to include the burden placed on caregivers, families and healthcare services in addition to increase the cost of care. ${ }^{[4,7,11]}$

Realizing the magnitude of delirium sequels for critically ill patients and their families as well as the health care organization would necessitate caregivers, policymakers, and researchers to unravel new era of delirium prevention using non-pharmacological strategies. Together with early identification of the risk factors, multidisciplinary team work that is accompanied by inattention and either a change in cognition or perceptual disturbance". ${ }^{[6]}$ It usually develops over a short period of time from hours to days and fluctuates over time. Together, the ICU and patients' related factors can contribute to delirium. Disruption of sleep cycle, use of physical restraints and immobilization are among ICUrelated factors of delirium. In addition to use of therapeutic maneuvers such as mechanical ventilator, insertion of invasive lines and medications (e.g. anticholinergics, analgesics, sedatives). Patients' related factors might also increase the risk to develop delirium such as severity of illness, age and co-morbidities. ${ }^{[4,7,8]}$



and application of updated evidences would establish definitive outcomes in preventing and treating delirium during the ICU stay to guarantee a better quality of life for critically ill patients post ICU discharge. ${ }^{[12-14]}$

Since delirium remains unrecognized in most of critically ill patients, vigilant nursing monitoring to assess the risk of delirium as well as the use of valid scales to diagnose delirium such as the Confusion Assessment Method for the ICU (CAM-ICU) are crucial. ${ }^{[7,13,15]}$ Use of evidence-based interventions to prevent delirium should not depend only on an individual physician's order but rather should be structured as a daily part of care with clearly defined safety strategy. ${ }^{[5,13]}$ The delirium prevention bundle is considered an essential intervention of the modern-day processes of care. Using such bundle allows optimization of critically ill patients' recovery, regaining their independence or help in peaceful death. Delirium prevention bundle consists of sedation cessation, pain control, early mobility, sleep promotion and sensory stimulation. ${ }^{[16,17]}$

Sensory stimulation is considered as one of the therapeutic 
tools used to prevent cognitive impairments. Its main goal is to provide similar environment that is close to the real world which cognitively stimulate critically ill patients in a safe and controlled manner. It includes visual, tactile, olfactory, gustatory and auditory stimulation. Using auditory stimulation as a non-pharmacological intervention can stimulate the affected neural networks, accelerate brain plasticity and avoid a sensory deprivation that could induce pain, agitation, and delirium and slow down the patients' recovery. ${ }^{[16-18]}$ Unfortunately, critically ill patients have experienced undesirable sounds in the ICU which could affect the recovery rates. In addition to stress and pain levels which will affect how the brain processes auditory signals. ${ }^{[19]}$

However, it is evident that familiar auditory stimuli by a family member voice is eliciting more responses to auditory tones as it can grasp patients' attention without much effort and disrupts ongoing cognitive activities. Familiar voices increase the activation in higher-level of cortical areas and stimulate long-term memory traces as these sounds are encoded in the critically ill patients' long-term memories. ${ }^{[20,21]}$ Furthermore, including emotional content in the voice messages to the patients may engage a higher level of cortical processing and trigger neural responses which in turn enhance the patients' attention. As delirium is featured with impaired short-term memory, impaired attention, and disorientation, using of familiar auditory stimuli is useful in preventing critically ill patients to develop delirium during their ICU stay. ${ }^{[19]}$

Accordingly, multicomponent family reorientation strategy has recently been proposed to achieve better outcomes. Family reorientation messages refer to the use family members' voice in orienting their patients to reality, providing a familiar, reassuring comfort, and assisting in counteracting the inattention, disorganized thinking in addition to memory and perceptual disturbances associated with the pathophysiological changes of delirium. ${ }^{[10]}$ Birge A and Aydin H (2019) rationalized providing an ongoing orientation to the critically ill patients through recorded family voice may assist the patients to interpret the ICU environment more accurately and then decrease the risk to develop delirium. ${ }^{[22]}$

The family engagement and empowerment component is added to the ABCDE bundle to become ABCDEF bundle for further improving of the quality of ICU care. The letter " $D$ " stands for assessment, prevention, and management of delirium which was previously existing in the bundle, while the letter " $F$ " is recently added to involve the family in decisionmaking and in care activities as lack of family engagement is a well-known risk factor for delirium in ICUs. ${ }^{[23]} \mathrm{A}$ recent study conducted by Krewulak KD et al. (2019) reported that family members could use assessment tool to assess delirium. ${ }^{[24]}$ In addition, family-patient communication as a management strategy is proven to reduce the incidence of delirium. ${ }^{[25]}$

International guidelines and protocols have new recommendations proposing changes in the way of the care delivered, challenging old paradigms and illuminating new unanswered questions that suggest the need for further research. Many studies focus on pharmacologic treatment of delirium while the effect of non-pharmacologic strategies has very few studies. ${ }^{[9,26,27]}$ Up to our knowledge, there are no national research have investigated the effect of family reorientation messages on delirium prevention among critically ill patients. Therefore, the aim of this study is to determine the effect of family reorientation messages on delirium prevention among critically ill patients.

\subsection{Aim of the study}

To determine the effect of family reorientation messages on delirium prevention among critically ill patients.

\subsection{Hypothesis of this study}

Patients who are subjected to family reorientation messages experienced no delirium in comparison with those who are not subjected.

\section{MATERIALS AND METHOD}

\subsection{Study design}

A quasi experimental research design was used in this study.

\subsection{Setting}

This study was carried out in two general adult ICUs in a selected university hospital in Alexandria-Egypt. In which policies and staff orientation programs were the same in both ICUs.

\subsection{Subjects}

A sample of 75 patients divided into three groups of patients; twenty-five patients were assigned the family voice group (FVG) to receive reorientation messages in a family member's voice, twenty-five patients received the same messages' content in an unfamiliar voice (unfamiliar voice group = UVG) and twenty-five patients (control group $=\mathrm{CG}$ ) who did not receive any reorientation messages. Patients were eligible if they were above 18 years old and intubated for more than 3 days. Exclusion criteria; patients diagnosed as brain dead, being unconscious, or have deafness. The study sample size was calculated by power analysis (Epi-info program); population size $=116$, expected frequency $=50 \%$, acceptable error $=10 \%$, confidence coefficient $=99 \%$, minimum sample size $=68$. 


\subsection{Measures}

One tool was used for data collection which is "Confusion Assessment Method- intensive care unit (CAM-ICU)".

Tool: Confusion Assessment Method-intensive care unit. The Confusion Assessment Method (CAM) was created in 1990, and it was intended to be a bedside assessment tool. Concurrent validation revealed a sensitivity of $94 \%-100 \%$ and specificity of $90 \%-95 \% .{ }^{[28]}$ The CAM-ICU is one of the recommended ICU delirium screening tools. This scale consists of four features, Feature 1: Acute change or fluctuating course of mental status, Feature 2: Inattention, Feature 3: Altered level of consciousness, and Feature 4: Disorganized Thinking. Using this tool, delirium is defined in terms of four diagnostic features, and is considered positive when Feature 1 and Feature 2 and either Feature 3 or 4 are present. In addition to the critically ill patients' characteristics such as age, sex, marital status, most significant family member to the patient, diagnosis, attached invasive devices, APACHEII, duration on mechanical ventilation and length of ICU stay.

\subsubsection{Audio Message content validity}

Five nursing experts in the critical care nursing specialty (clinical staff in ICUs and in the Faculty of Nursing) assessed the reorientation messages script content before conducting the study and the necessary modifications were done accordingly. The script was originally developed in the Arabic language by the researchers. Patients in the two groups received the messages in the Arabic language. A pilot study was carried out on ten percent of patients $(\mathrm{N}=8)$ in order to identify obstacles and problems that may be encountered during data collection.

\subsubsection{Audio message content}

Each message either recorded in the family member's voice (significant family member who were related to the patient by blood, or marriage) or the unknown voice was last for two minutes only. It included three components which are ordered randomly; patient orientation, family issues, and reassurance words. Patient orientation included orientation to the person who records the message, patient's name, day, date and time, the ICU environment, orientation to the attached tubes, and the reason for stay. Second component is family issues; life events occur in the family. Last component is reassurance words such as "Don't be scared, we are here outside the ICU going in \& out to look after you". In UVG, the family issues component of the message was discussed earlier to message recording by the researcher with the most significant family member.

Published by Sciedu Press

\subsection{Study procedures}

Each message was delivered only during daytime hours (not to disturb sleep time or interrupt family visits). Each message was applied hourly during the day time beginning from 10:00 am till 5:00 pm and repeated for 5 consecutive days. The head set was noise reducing set to avoid the effect of extraneous environmental noise. The control group was left to the ICU routine nursing care.

Delirium was screened twice by the researcher using CAMICU; before and after the intervention. Throughout the five days of data collection, screening for delirium was done for the three groups. If CAM-ICU criteria were met, patient was considered positive for delirium. If delirium criteria were not met, patient was considered negative for delirium.

\subsection{Administrative design and ethical considerations}

The study was approved by the administrative authorities of the selected hospital to collect the data. Data were collected in a period of nine months from the beginning of April 2018 to the end of December 2018. Signed consent was obtained from the patients. Confidentiality of the information, anonymity of the patient, and the right to participate, refuse or withdraw from the study at any time were guaranteed. Consent has been also obtained from family members who were participated in recording the messages.

\subsection{Statistical analysis of the data}

Data were fed to the computer and analyzed using IBM SPSS software package version 20.0. (Armonk, NY: IBM Corp). Qualitative data were described using number and percent. Quantitative data were described using mean, standard deviation. Significance of the obtained results was judged at the $5 \%$ level.

The used tests were

1) Chi-square test: For categorical variables, to compare between different groups.

2) Monte Carlo correction: Correction for chi-square when more than $20 \%$ of the cells have expected count less than 53 .

\section{Results}

As shown in Table 1, more than three quarters of patients in the control and family group and $52 \%$ of the unfamiliar voice group aged less than 69 years old. There was no statistical difference between the three groups of patients related to the sex and marital status $\left(p=.234,{ }^{M C} p=.437\right)$. Each patient had more than one significant family member, however, daughter was the most significant family member in $52 \%$ of the control group, $44.4 \%$ of the family voice group and $36 \%$ of the unfamiliar voice group. Majority of the control, family voice, and unfamiliar voice groups of patients recruited to 
ICU with medical diagnoses $(88 \%, 100 \%, 84 \%)$ respectively. tween the three studied groups $(p=.685)$. Number of days It was shown that there were no statistical differences be- whilst in ICU stay didn't differ between the three studied tween the studied groups of patients related to the severity groups $(p=.121)$. of their illness measured using APACHE II $(p=.134)$. The number of days on mechanical ventilation didn't differ be-

Table 1. Demographics and clinical characteristics of all patients in the control, family voice, and unfamiliar voice groups

\begin{tabular}{|c|c|c|c|c|c|c|c|c|}
\hline \multirow{3}{*}{ Item } & \multicolumn{6}{|c|}{ Study groups $(n=75)$} & \multirow{3}{*}{ Test of sig. } & \multirow{3}{*}{$p$} \\
\hline & \multicolumn{2}{|c|}{$\begin{array}{l}\text { Control group } \\
(n=25)\end{array}$} & \multicolumn{2}{|c|}{$\begin{array}{l}\text { Family voice } \\
(n=25)\end{array}$} & \multicolumn{2}{|c|}{$\begin{array}{l}\text { Unfamiliar voice } \\
(n=25)\end{array}$} & & \\
\hline & No. & $\%$ & No. & $\%$ & No. & $\%$ & & \\
\hline \multicolumn{9}{|c|}{ Age (Years) } \\
\hline$<30$ & 1 & 4.0 & 0 & 0.0 & 3 & 12 & & \multirow{4}{*}{${ }^{\mathrm{MC}} p=.061$} \\
\hline $30-\leq 39$ & 1 & 4.0 & 0 & 0.0 & 6 & 24.0 & \multirow{3}{*}{$\chi^{2}=12.514$} & \\
\hline $40-\leq 49$ & 4 & 16.0 & 6 & 22.2 & 3 & 12.0 & & \\
\hline $50-<60$ & 19 & 76.0 & 19 & 77.8 & 13 & 52.0 & & \\
\hline \multicolumn{9}{|l|}{ Sex } \\
\hline Male & 9 & 36.0 & 13 & 52.0 & 15 & 60.0 & \multirow{2}{*}{$\chi^{2}=2.904$} & \multirow{2}{*}{.234} \\
\hline Female & 16 & 64.0 & 12 & 48.0 & 10 & 40.0 & & \\
\hline \multicolumn{9}{|c|}{ Marital status } \\
\hline Married & 22 & 88.0 & 25 & 100.0 & 24 & 96.0 & \multirow{2}{*}{$\chi^{2}=2.305$} & \multirow{2}{*}{${ }^{\mathrm{MC}} p=.437$} \\
\hline Single & 3 & 12.0 & 0 & 0.0 & 1 & 4.0 & & \\
\hline \multicolumn{9}{|c|}{ Most significant family member } \\
\hline Sister & 7 & 28.0 & 4 & 16.7 & 4 & 16.0 & $\chi^{2}=1.331$ & .514 \\
\hline Daughter & 13 & 52.0 & 11 & 44.4 & 7 & 28.0 & $\chi^{2}=3.081$ & .214 \\
\hline Wife & 8 & 32.0 & 7 & 27.8 & 9 & 36.0 & $\chi^{2}=0.326$ & .850 \\
\hline Husband & 5 & 20.0 & 4 & 16.7 & 3 & 12.0 & $\chi^{2}=0.677$ & ${ }^{\mathrm{MC}} p=.781$ \\
\hline Mother & 2 & 8.0 & 3 & 11.1 & 4 & 16.0 & $\chi^{2}=0.834$ & ${ }^{\mathrm{MC}} p=.886$ \\
\hline Father & 2 & 8.0 & 0 & 0.0 & 1 & 4.0 & $\chi^{2}=1.347$ & ${ }^{\mathrm{MC}} p=.780$ \\
\hline Brother & 4 & 16.0 & 3 & 11.1 & 2 & 8.0 & $\chi^{2}=0.834$ & ${ }^{\mathrm{MC}} p=.886$ \\
\hline Son & 8 & 32.0 & 10 & 38.9 & 9 & 36.0 & $\chi^{2}=0.226$ & ${ }^{\mathrm{MC}} p=.893$ \\
\hline \multicolumn{9}{|c|}{ Reason for admission } \\
\hline Medical & 22 & 88.0 & 25 & 100.0 & 21 & 84.0 & \multirow{3}{*}{$\chi^{2}=4.650$} & \multirow{3}{*}{${ }^{\mathrm{MC}} p=.224$} \\
\hline Surgical & 1 & 4.0 & 0 & 0.0 & 0 & 0.0 & & \\
\hline Trauma & 2 & 8.0 & 0 & 0.0 & 4 & 16.0 & & \\
\hline \multicolumn{9}{|c|}{ APACHE II score } \\
\hline$>24$ & 9 & 36.0 & 3 & 12.0 & 5 & 22.2 & \multirow{2}{*}{$\chi^{2}=4.025$} & \multirow{2}{*}{.134} \\
\hline$<24$ & 16 & 64.0 & 22 & 88.0 & 20 & 77.8 & & \\
\hline \multicolumn{9}{|c|}{ Duration of mechanical ventilation (days) } \\
\hline$<3$ & 15 & 60.0 & 18 & 72.2 & 17 & 68.0 & \multirow[t]{2}{*}{$\chi^{2}=0.757$} & \multirow[t]{2}{*}{.685} \\
\hline$\geq 3$ & 10 & 40.0 & 7 & 27.8 & 8 & 32.0 & & \\
\hline \multicolumn{9}{|c|}{ ICU length of stay(days) } \\
\hline$<3$ & 11 & 44.0 & 18 & 72.0 & 12 & 48.0 & $2=4210$ & 121 \\
\hline$\geq 3$ & 14 & 56.0 & 7 & 28.0 & 13 & 52.0 & $=4.219$ & .121 \\
\hline
\end{tabular}

Note. $\chi^{2}$ : Chi square test; MC: Monte Carlo; $p: p$ value for comparing between the studied groups; ${ }^{*}$ : Statistically significant at $p \leq .05$. 
In Figure 2 the mean number of vascular access was 3.67 in the control group. While in the unfamiliar voice group was 3.22 and 3 in the family voice group. The mean number of family members who were visiting the patients was 5.72 in the control group and 6.08 in the unfamiliar voice group. Whilst in the family voice group, the mean number of visitors was 9.28 (see Figure 3).
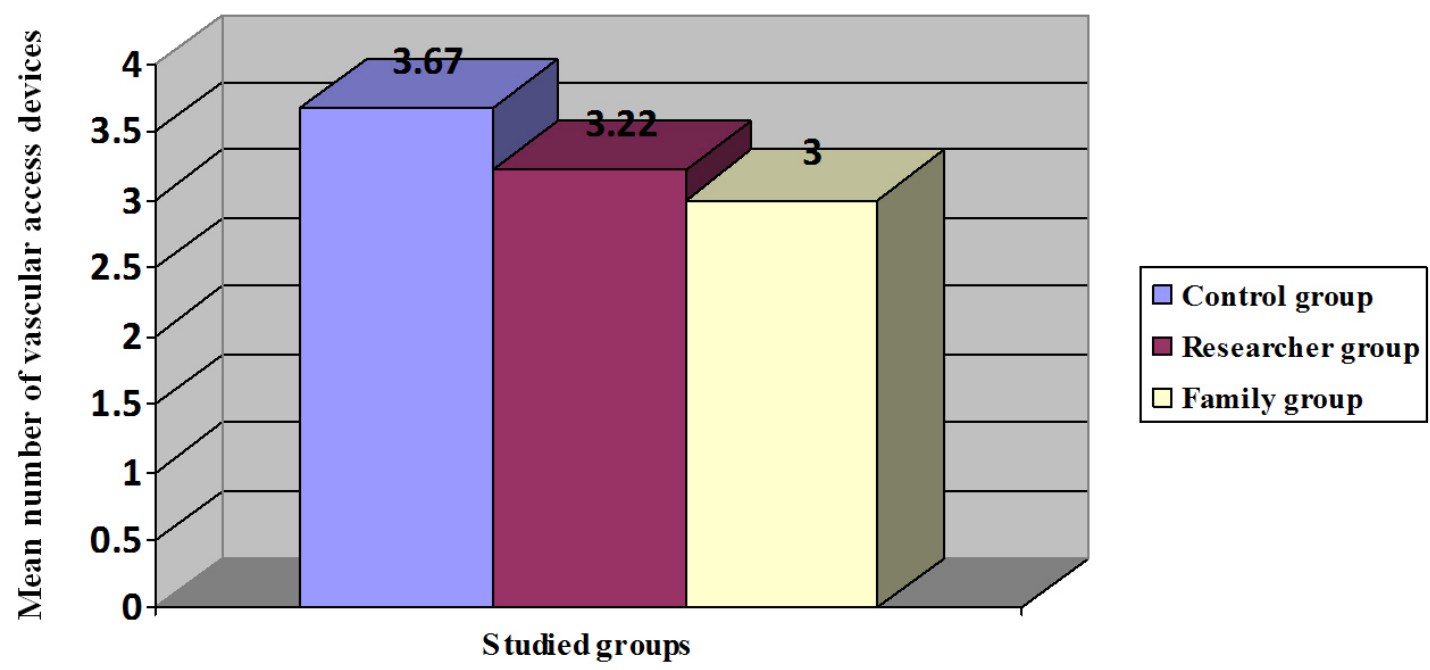

Figure 2. Number of vascular access in the patients' groups

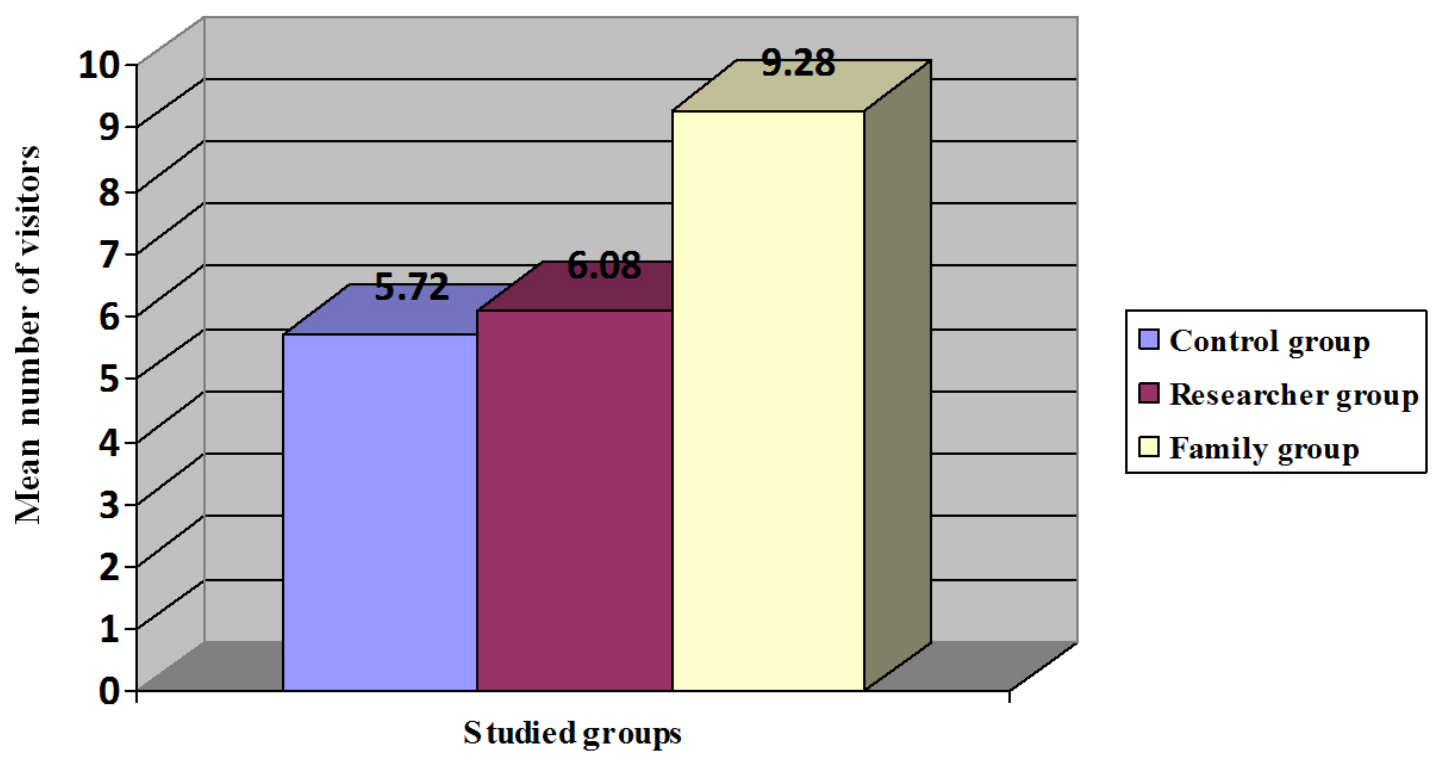

Figure 3. Number of family visitors in the patients' groups

By the first day of ICU stay, $12 \%$ of patients in the control group experienced delirium while all patients in both groups; the family voice and unfamiliar voice group experienced no delirium. On the fifth day of patients' ICU stay, delirium occurrence rates were again comparable with a statistically significant difference between the three groups $(p \leq .001)$, in which the delirium rate in the family voice group was the same as the first day $(0 \%)$ with an increase in the unfamiliar voice group to $28 \%$. Such increase in the delirium rate was also observed in the control group (64\%) by the fifth day. During the five-day intervention period, the delirium free days was all the days in the family voice group, four days in the unfamiliar voice group and no free days in the control group which indicating a significant statistical difference among the three groups on number of delirium free days $\left({ }^{M C} p<.001^{*}\right)$ (see Table 2$)$. 
Table 2. Patients delirium assessments whilst in ICU

\begin{tabular}{|c|c|c|c|c|c|c|c|c|}
\hline \multirow{3}{*}{$\begin{array}{l}\text { Delirium in ICU } \\
\mathbf{1}^{\text {st }} \text { day }\end{array}$} & \multicolumn{6}{|c|}{ All patient participants $(n=75)$} & \multirow{2}{*}{$\chi^{2}$} & \multirow{2}{*}{$p$} \\
\hline & \multicolumn{2}{|c|}{ Control $(n=25)$} & \multicolumn{2}{|c|}{ Family voice $(n=25)$} & \multicolumn{2}{|c|}{ Unfamiliar voice $(n=25)$} & & \\
\hline & & & & & & & & \\
\hline No delirium & 22 & $(88 \%)$ & 25 & $(100 \%)$ & 25 & $(100 \%)$ & $18.159^{*}$ & ${ }^{\mathrm{MC}} p<.001^{*}$ \\
\hline Delirium & 3 & $(12 \%)$ & 0 & $(0 \%)$ & 0 & $(0 \%)$ & & \\
\hline \multicolumn{9}{|l|}{$2^{\text {nd }}$ day } \\
\hline No delirium & 15 & $(60 \%)$ & 25 & $(100 \%)$ & 25 & $(100 \%)$ & $18.159^{*}$ & ${ }^{\mathrm{MC}} p<.001^{*}$ \\
\hline Delirium & 10 & $(40 \%)$ & 0 & $(0 \%)$ & 0 & $(0 \%)$ & & \\
\hline \multicolumn{9}{|l|}{$3^{\text {rd day }}$} \\
\hline No delirium & 15 & $(60 \%)$ & 25 & $(100 \%)$ & 25 & $(100 \%)$ & $18.159^{*}$ & ${ }^{\mathrm{MC}} p<.001^{*}$ \\
\hline Delirium & 10 & $(40 \%)$ & 0 & $(0 \%)$ & 0 & $(0 \%)$ & & \\
\hline \multicolumn{9}{|l|}{$4^{\text {th }}$ day } \\
\hline No delirium & 15 & $(60 \%)$ & 25 & $(100 \%)$ & 25 & $(100 \%)$ & $18.159^{*}$ & ${ }^{\mathrm{MC}} p<.001^{*}$ \\
\hline Delirium & 10 & $(40 \%)$ & 0 & $(0 \%)$ & 0 & $(0 \%)$ & & \\
\hline \multicolumn{9}{|l|}{$5^{\text {th }}$ day } \\
\hline No delirium & 9 & $(36 \%)$ & 25 & $(100 \%)$ & 18 & $(72 \%)$ & $25.271^{*}$ & ${ }^{\mathrm{MC}} p<.001^{*}$ \\
\hline Delirium & 16 & $(64 \%)$ & 0 & $(0 \%)$ & 7 & $(28 \%)$ & & \\
\hline
\end{tabular}

Note. $\chi^{2}$ : Chi square test; MC: Monte Carlo; $p: p$ value for comparing between the studied groups; *: Statistically significant at $p \leq .05$

\section{Discussion}

Delirium has a strong nursing focus during its assessment and management. ${ }^{[5,29]}$ In this study, there was a focus to implement a non-pharmacological intervention to reduce delirium by the family members. Several studies investigated the effect of reorientation audio message by family members on the consciousness level in comatose head injured patients. ${ }^{[16,23,24]}$ Kevic K and Namic E (2018) found that GCS becomes higher with the application of auditory stimulation in comatose patients. ${ }^{[30]}$ Pape et al. study, 2015 examined the effects of auditory stimulation program on level of consciousness of acute traumatic brain injured patients. They found that there is an improvement in neurobehavioral performance in the study group compared to the control group. ${ }^{[31]}$ Moreover, other studies provide strong recommendations that multimodal sensory stimulation improves the alertness and arousal of vegetative states patients after traumatic brain injuries. ${ }^{[31,32]}$ The current study concerned with studying the effect of auditory reorientation messages by the family members' voice on delirium prevention. The current study findings show no significant difference in the three studied groups regarding age, APACHE II, duration of mechanical ventilation, and ICU length of stay. However, it can be seen that there is a higher APACHE II, ICU length of stay, duration of mechanical ventilation in the control group compared to the family voice or even the unfamiliar voice group.

The main findings of the current study denote that the family voice group were free of delirium during the 5 days of the data collection compared to the unfamiliar voice group. On the contrary, the control group patients started to develop delirium from the first day of data collection and the percent increased by the 5 th day. This highlights the importance of reorienting the patients to the family issues starting from ICU admission. This might increase their alertness and reduce sensory deprivation thus maintain their stimulation and connection to the external environment.

These findings are in line with a study conducted by Mitchel et al. (2017) which focused on a family intervention to reduce delirium by using orientation, memory clues and cognitive or therapeutic stimulation. ${ }^{[10]}$ Also a study conducted by Eghbali-Babadi et al, 2017 highlighted the importance of effective communication between the patient and the family as a non-medical management method which really reduced the occurrence of delirium after cardiac surgery. ${ }^{[25]}$ Another study done by Birge A and Aydin H (2019) concluded that nurses' ability to perform non-pharmacological intervention orientation by supporting visits from family and friends was effective in reducing the incidence of delirium. This describes the role of the family participation in patient management to preventing complications following ICU admission. ${ }^{[22]}$

It has been reported in many studies that patients' immobility, use of urinary catheterization, use of vascular devices are significant risk factors to develop delirium as a result of immobility. The current study findings are in line with these 
studies as this factor is already an existing factor in all groups and patients in the unknown voice group and control groups developed delirium. This might be due to the prolonged immobility and pain accompanied with these devices that may lead to delirium. ${ }^{[33,34]}$ On the other side, the family voice group did not develop delirium although the mean number of vascular access devices in this group is not significantly different from the other two groups. This could be due to the reorientation messages given by the family members.

Several studies found that extended family visits reduce the incidence of delirium significantly therefore reduce the duration of ICU stay. These studies did not focus on any kind of stimulation but focusing on allowing a family presence for a longer time which promote patient family interaction thus maintaining brain stimulation with family members. ${ }^{[22,35,36]}$ The current study findings are in line with these studies as family voice group had a higher mean number of visitors than the two other groups. This can be described as the more family members, the more cognitive stimulation and more alertness thus creating a healing environment.

The current study approved the hypothesis that using auditory stimulation by audio message help the patients to be more oriented to the surrounded environment especially if the message has been displayed by a family voice member including family issues. Therefore, the crucial goal of this study is to prevent the occurrence of delirium thus improving the clinical outcomes of critically ill patients including shorter duration of ICU stay, shorter duration of mechanical ventilation and thus lower the ICU cost.

\subsection{Implications to practice}

- Use of non-pharmacological nursing interventions that contribute in delirium prevention is desirable.

- Family members are preferably suited to conduct early reorientation message to prevent delirium for their patients during ICU stay.
- Critical care nurses were more likely to endorse family involvement in patients' care in the study settings.

\subsection{Limitations to the study}

Small sample size in this study which limits the generalization of the findings. Also, the clinical trial lacks to randomization of the subjects.

\section{Conclusion}

Reorienting critically ill patients through recorded messages is an effective strategy to reduce the incidence of delirium. Furthermore, using a familiar family sound is more effective in reducing delirium as proved by the findings of the current study. During the five-day intervention period, the family voice group shows more delirium free days than the unfamiliar voice group. The intervention used in this study is easy, costless and effective strategy in prevention of delirium among critically ill patients. This intervention is one of the non-pharmacological strategies that can be used by critical care nurses instead of using pharmacological management which is a focus of delirium management.

\section{Recommendations}

The intervention of reorientation family message should be a nursing care focus in ICUs parallel with pharmacological management of delirium. Replication of this study on larger sample size is guaranteed to allow generalization of the findings and confirm the effect of the intervention. Moreover, further research should be conducted to investigate whether the intervention prevent the delirium for more days during the ICU length of stay till discharge. Because families are also a focus of care alongside their patients, studies to investigate the impact of family engagement in patient care on the families' outcomes should be conducted.

\section{CONFlicts of InTEREST Disclosure}

The authors declare that there is no conflict of interest.

\section{REFERENCES}

[1] Nurses A.A.o.C.C, Bell L. AACN scope and standards for acute and critical care nursing practice. American Association of Critical-Care Nurses. 2015.

[2] Tembo AC. The experience of cognitive impairment in critically ill patients in and beyond intensive care: findings from a larger phenomenological study. Journal of Nursing. 2015; 2(1): 1. https : //doi.org/10.7243/2056-9157-2-1

[3] Acevedo-Nuevo M, et al. The early diagnosis and management of mixed delirium in a patient placed on ECMO and with difficult sedation: A case report. Intensive Crit Care Nurs. 2018; 44: 110-114.

Published by Sciedu Press
PMid:28869145 https://doi.org/10.1016/j.iccn.2017.07 .013

[4] Fan Y, et al. A review: Nursing of intensive care unit delirium. J Neurosci Nurs, 2012; 44(6): 307-16; quiz E9-10. https://doi .or $\mathrm{g} / 10.1097 / \mathrm{JNN}$. 0b013e318274cc4d

[5] Blevins CS, DeGennaro R. Educational Intervention to Improve Delirium Recognition by Nurses. American Journal of Critical Care. 2018; 27(4): 270-278. PMid:29961661 https://doi.org/10.4037/aj cc2018851

[6] Association AP. Diagnostic and statistical manual of mental disorders (DSM-5®). American Psychiatric Pub; 2013. 
[7] Volland J, Fisher A, Drexler D. Delirium and Dementia in the Intensive Care Unit: Increasing Awareness for Decreasing Risk, Improving Outcomes, and Family Engagement. Dimensions of Critical Care Nursing. 2015; 34(5): 259-264. PMid:26244239 https : //doi.org/10.1097/DCC.0000000000000133

[8] $\mathrm{Kim} \mathrm{H}$, et al. The major risk factors for delirium in a clinical setting. Neuropsychiatric Disease and Treatment. 2016; 12: 1787-1793. PMid:27499625 https://doi.org/10.2147/NDT .S112017

[9] Salluh JI, et al. Outcome of delirium in critically ill patients: systematic review and meta-analysis. BMJ. 2015; 350: 2538 PMid:26041151 https://doi.org/10.1136/bmj.h2538

[10] Mitchell ML, et al. A family intervention to reduce delirium in hospitalised ICU patients: A feasibility randomised controlled trial. Intensive Crit Care Nurs. 2017; 40: 77-84. PMid:28254205 https://doi.org/10.1016/j.iccn.2017.01.001

[11] Hickin SL, White S, Knopp-Sihota J. Nurses' knowledge and perception of delirium screening and assessment in the intensive care unit: Long-term effectiveness of an education-based knowledge translation intervention. Intensive Crit Care Nurs. 2017; 41: 4349. PMid:28434804 https://doi.org/10.1016/j.iccn. 2017 03.010

[12] Arumugam S, et al. Delirium in the intensive care unit. Journal of Emergencies, Trauma, and Shock. 2017; 10(1): 37. PMid:28243012 https://doi.org/10.4103/0974-2700.199520

[13] Sarutzki-Tucker A, Ferry R. Beware of Delirium. The Journal for Nurse Practitioners. 2014; 10(8): 575-581. https ://doi.org/10 $.1016 / j$.nurpra. 2014.07.003

[14] Rivosecchi RM, et al. Nonpharmacological Interventions to Prevent Delirium: An Evidence-Based Systematic Review. Critical Care Nurse. 2015; 35(1): 39-49. PMid:25639576 https ://doi .org/10 $.4037 / \mathrm{ccn} 2015423$

[15] Yang J, et al. Risk Factors of Delirium in Sequential Sedation Patients in Intensive Care Units. Bio Med Research International. 2017.

[16] Smith CD, Grami P. Feasibility and Effectiveness of a Delirium Prevention Bundle in Critically Ill Patients. Am J Crit Care. 2016 26(1): 19-27. PMid:27965224 https://doi.org/10.4037/ajcc 2017374

[17] Delgado SA. Preventing Delirium in Critically Ill Patients. American Journal of Critical Care. 2017; 26(1): 30. PMid:27965226 https://doi.org/10.4037/ajcc2017371

[18] Turon M, et al. Cognitive stimulation in ICU patients: should we pay more attention? Bio Med Central. 2013.

[19] Pape TL, et al. Preliminary framework for Familiar Auditory Sensory Training (FAST) provided during coma recovery. The Journal of Rehabilitation Research and Development. 2012; 49(7): 1137. https://doi.org/10.1682/JRRD . 2011.08.0154

[20] Mohammadi MK, et al. Effects of Organized Auditory Stimulation by Familiar Voice on Blood Pressure and Body Temperature in Comatose Patients. Journal of Holistic Nursing and Midwifery. 2017; 27(1): 95-102. https://doi.org/10.18869/acadpub.h $\mathrm{nmj} \cdot 27.1 .95$

[21] Tavangar H, et al. Effect of family members' voice on level of consciousness of comatose patients admitted to the intensive care unit: A single-blind randomized controlled trial. Advanced Biomedical Research. 2015; 4: 106-106.

[22] Ozturk BA, Tel AH. The effect of nonpharmacological training on delirium identification and intervention strategies of intensive care nurses. Intensive Crit Care Nurs. 2017; 41: 33-42. PMid:28214083 https://doi.org/10.1016/j.iccn.2016.08.009
[23] Henderson P. Nurses' Role in Implementing the ABCDEF Bundle. Crit Care Nurse. 2019; 39(3): 13. PMid:31154324 https: //doi.org/10.4037/ccn2019760

[24] Krewulak KD, et al. Feasibility and acceptability of family administration of delirium detection tools in the intensive care unit: a patient-oriented pilot study. CMAJ Open. 2019; 7(2): e294-e299. PMid:31028053 https ://doi.org/10.9778/cmajo. 20180123

[25] Eghbali-Babadi M, Shokrollahi N, Mehrabi T. Effect of family-patient communication on the incidence of delirium in hospitalized patients in cardiovascular surgery ICU. Iranian Journal of Nursing and Midwifery Research. 2017; 22(4): 327. PMid:28904548 https://doi.org/10.4103/1735-9066.212985

[26] Mesa $P$, et al. Delirium in a Latin American intensive care unit. A prospective cohort study of mechanically ventilated patients. Revista Brasileira de Terapia Intensiva. 2017; 29(3): 337-345. PMid:29044304 https://doi.org/10.5935/0103-507X. 2017 0058

[27] Barbateskovic M, et al. Pharmacological interventions for delirium in intensive care patients: a protocol for an overview of reviews. Systematic Reviews. 2016; 5(1): 211. PMid:27923397 https://doi.org/10.1186/s13643-016-0391-5

[28] Inouye SK, et al. Clarifying confusion: the confusion assessment method: a new method for detection of delirium. Annals of Internal Medicine. 1990; 113(12): 941-948. PMid:2240918 https: //doi.org/10.7326/0003-4819-113-12-941

[29] Lamond E, Murray S, Gibson CE. Delirium screening in intensive care: A life saving opportunity. Intensive Crit Care Nurs. 2018; 44: 105-109. PMid:28587754 https://doi.org/10.1016/j.ic cn.2017.04.014

[30] Cevik K, Namik E. Effect of Auditory Stimulation on the Level of Consciousness in Comatose Patients Admitted to the Intensive Care Unit: A Randomized Controlled Trial. J Neurosci Nurs. 2018; 50(6): 375-380. PMid:30407969 https://doi .org/10.1097/JN N. 0000000000000407

[31] Pape TLB, et al. Placebo-controlled trial of familiar auditory sensory training for acute severe traumatic brain injury: a preliminary report. Neurorehabilitation and Neural Repair. 2015; 29(6): 537-547. PMid:25613986 https://doi .org/10.1177/15459683145546 26

[32] Padilla R, Domina A. Effectiveness of sensory stimulation to improve arousal and alertness of people in a coma or persistent vegetative state after traumatic brain injury: a systematic review. American Journal of Occupational Therapy. 2016; 70(3). PMid:27089287 https://doi.org/10.5014/ajot.2016.021022

[33] Khera R, et al. Trends in the use of percutaneous ventricular assist devices: analysis of national inpatient sample data, 2007 through 2012. JAMA Internal Medicine. 2015; 175(6): 941-950. PMid:25822170 https://doi.org/10.1001/jamainternmed.2014.7856

[34] Khazanie P, et al. Trends in the use and outcomes of ventricular assist devices among medicare beneficiaries, 2006 through 2011. Journal of the American College of Cardiology. 2014; 63(14): 1395-1404. PMid:24486278 https://doi.org/10.1016/j . jacc.2013.12 .020

[35] Schwanda M, Gruber R. Extended visitation policy may lower risk for delirium in the intensive care unit. Evidence-Based Nursing. 2018; 21(3): 80-80. PMid:29592860 https://doi .org/10.1136/eb-2 018-102884

[36] Smithburger PL, et al. Perceptions of Families of Intensive Care Unit Patients Regarding Involvement in Delirium-Prevention Activities: A Qualitative Study. Critical Care Nurse. 2017; 37(6): e1-e9. PMid:29196594 https://doi.org/10.4037/ccn2017485 